\title{
Development and Validation of a Social Intelligence Inventory
}

\author{
Erwin P. Lacanlale
}

\begin{abstract}
This research developed and validated a Social Intelligence Inventory that could serve as an instrument in identifying the dominant type of social intelligence possessed by an individual. To some extent, this inventory would help teachers in assessing their students' social inclination and social competencies.

This study is a research and development project ( $R$ and $D)$. In conducting the study, efforts were made to present the study as objectively as possible and where a Social Intelligence Inventory was administered among the subject students for validation. Also established were its content validity and reliability. The subjects of this study were selected students from the Tarlac State University presently enrolled during the second semester of the school year 2005-2006. The subjects were taken as cross section sample from first year to fourth year level. Based on the findings of this study, it was concluded that the items constructed in the developed social intelligence inventory represented the different areas of social intelligence of college students. The items in the scale discriminated the students as to the indicators of social intelligence and they were all statistically valid. The experts rated the scale very satisfactory and it has a very high reliability index.
\end{abstract}

Index Terms-Development and validation, inventory, social intelligence, social quotient.

\section{INTRODUCTION}

It has become a truism that "no two individuals are exactly alike". Individuals are born distinct from each other and are unique in their own way. The factor of being distinct and unique from one another has sometimes become a big factor why problems in dealing and relating to other people arise. But as a social being, man cannot refrain from socializing with others in his social environment. He needs to relate and interact with others interpersonally for his survival, growth and development.

That "No man is an island," shows man's relationship to other people as very important. He needs to make adjustments in relating to others in various situations to sustain and maintain his relationship. His interpersonal relationship with others affects his relationship towards himself. His self-concept, self-esteem, and self-efficacy are being influenced by his relationship to other people. Man is a social being, and in his everyday living, he comes to meet and interact with different types of people with different personalities. Individuals vary in physical as well as in psychological and social characteristics. Because of individual differences, man comes to experience

Manuscript received October 20, 2012; revised January 13, 2013.

Erwin P. Lacanlale is with Tarlac State University, Philippines (email:erwinplacanlale@yahoo.com,win1179_tsu@yahoo.com). misunderstandings, conflicts, quarrels and frustrations in life if he cannot manage and direct his social relations. The problem in meeting individual differences has now become prevalent in every group and society. Compromising differences, resolving conflicts, and enhancing personal and social relations have now become a challenge to every individual. Because of these, man needs to become adaptive and flexible in dealing with others to develop healthy and smooth relationships. He needs to develop and possess the capacity and ability to understand and manage other people. He needs to know how to operate and handle various situations, and he should have an idea about his social environment where he is interacting. To respond to these needs, man's social intelligence is deemed to be important.

Social intelligence is the human capacity to understand what is happening in the world and responding to that understanding in a personally and socially effective manner. Thorndike (1920) maintained that there are three types of intelligences; these are the abstract, mechanical and social intelligence. Thorndike originally coined social intelligence and defined it as the person's ability to understand and manage other people, and engage in adaptive social interactions. It is the ability to act wisely in human relations. $\mathrm{He}$ maintained that social intelligence is different from academic ability and a key element in what makes people succeed in life [1].

Moss and Hunt (1927) defined social intelligence as the "ability to get along with others [2]." More recently, Kihlstrom and Cantor (1987) redefined social intelligence to refer to the individuals' fund of knowledge about the social world [3]. Gardner (1983), in his Frames of Mind: Multiple Intelligences has proposed that intelligence is not a unitary cognitive ability, but there are seven or perhaps more quite different kinds of intelligence. Multiple Intelligences, according to Gardner, are the individual differences' constructs in which some people or some groups are assumed to have more of these abilities than others [4]. Among the seven intelligences he mentioned was social intelligence or interpersonal intelligence. Interpersonal intelligence, as referred to by Gardner, is the individual's ability to notice and make distinctions among other individuals. Accordingly, the social intelligence view construes individual differences in social behavior, the public manifestations of personality, to be the product of individual differences in the knowledge which individuals bring to bear on their social interactions. Differences in social knowledge cause variations in social behavior, but it does not make sense to construct measures of social IQ. The important variable is not how much social intelligence the person has, but rather what social intelligence he or she possesses (Kihlstrom and Cantor, 1987) [3]. 
Recently, Karl Abrecht (2005) contends that people have lost jobs, friends, marriages, and mates because of social incompetence. That people who have highly developed sense of social intelligence have more friends, better relationships, more successful careers, and happier lives than those who lack those skills [5].

Social intelligence is now opening a new door and is becoming an interesting topic in the field of education and industrial organizations where human interactions and relations are often taking place. Human communication and relation have become one of the pressing problems in school, industrial organization, politics and other walks of social life. It is in this light why the researcher wants to contribute and be a part in the unfolding of a new facet on human intelligence through an inventory test which the researcher believes that the test can help in the assessment of social quotient as well as to contribute in understanding and enhancing human social behaviors and relations.

\section{StATEMENT OF OBJECTIVES}

This research aimed to develop and validate a social intelligence inventory. It specifically sought to answer and accomplish the following objectives:

1) To develop a Social Intelligence Inventory for College Students based on:

a. literature; and

b. experts' contributions

2) To validate the items of the proposed Social Intelligence Inventory by:

a. content analysis based from the area of social intelligence

b. item analysis; and

c. experts' validation

3) To establish the reliability index of the scale by internal consistency.

\section{SignificAnCE OF THE STUdy}

The ultimate beneficiaries of this study are the respondents themselves, for this study would help them assess and determine their social quotient. This could give them an idea about themselves in their social environment, how they behave and relate to others, and how do they see or view others in their social world.

Other college students could also benefit from this study since they can use the inventory in determining the social intelligence they possess for them to know and understand themselves and others better. This study would be essential to parents and teachers because they could gain information and insights from the findings of this study. Through the inventory, they could determine the social competence of their children and students.Educational institutions, political and industrial organizations could also utilize the findings of this study and the inventory in determining the social competency of their clienteles.

This study would be of utmost importance to future researchers and students who intended to pursue similar studies. Finally, this study would contribute greatly to the Philippine society and mankind in general as a vital instrument and element towards individual and social development.

\section{DISCUSSION}

\section{A. Development of the Social Intelligence Inventory}

\section{1) Items from related literature}

The researcher carefully reviewed and analyzed literature on social intelligence which served as basis and guide in the construction of the items in the inventory. These related literatures were derived from books, studies, and internet materials.

\section{2) Items from the experts}

Five experts were consulted. They corrected and suggested more items in the initial draft of the inventory. These experts are social scientists who specialized in the field of psychology and sociology. They were provided with the first draft of the inventory where the characteristics or attributes of socially intelligent individuals were stated and listed. The experts were asked to write their suggestions and additional statements that were not included in the list. The experts checked those characteristics in the inventory which they believed are correct and worthy of inclusion in the test. Some items were refined and corrected by the experts, some were deleted because they perceived them to be inappropriate. Also, the experts provided some statements/items that were included in the second draft of the inventory.

\section{3) Initial inventory}

The items in the initial inventory were expressed in just one statement. However, there was a little difficulty in finalizing the items to be included in the initial list. Some items were found to be somewhat similar with the other items and some did not implicitly characterize the distinctiveness or personality of socially intelligent individuals on particular areas of social intelligence. This difficulty was resolved through integrating and incorporating the corrections and the suggested items given by the experts.

The table revealed the indicators per area of social intelligence. In the area of social sensitivity, twelve (12) items were derived from literature and six (6) items were from experts; under social communication, nine (9) items were taken from literature and eighteen items from experts; under social influence twelve (12) were taken from literature and eight (8) from experts; under social efficacy, eleven items were taken from literature and six (6) items from experts; under social catalyst, twelve (12) items were taken from literature and eight (8) items from the experts and in the area of social advancement, seven items came from literature and eleven (11) items from the experts.

From all the areas of social intelligence, there were sixtythree (63) items derived from literature and forty-seven (47) items from the experts. There was a total of one hundred ten (110) items comprising the initial inventory. The data signified that more items in the inventory were derived from literature as compared to the items contributed by the experts. But obviously, the difference was minimal. 
TABLE I: SOURCES OF ITEMS

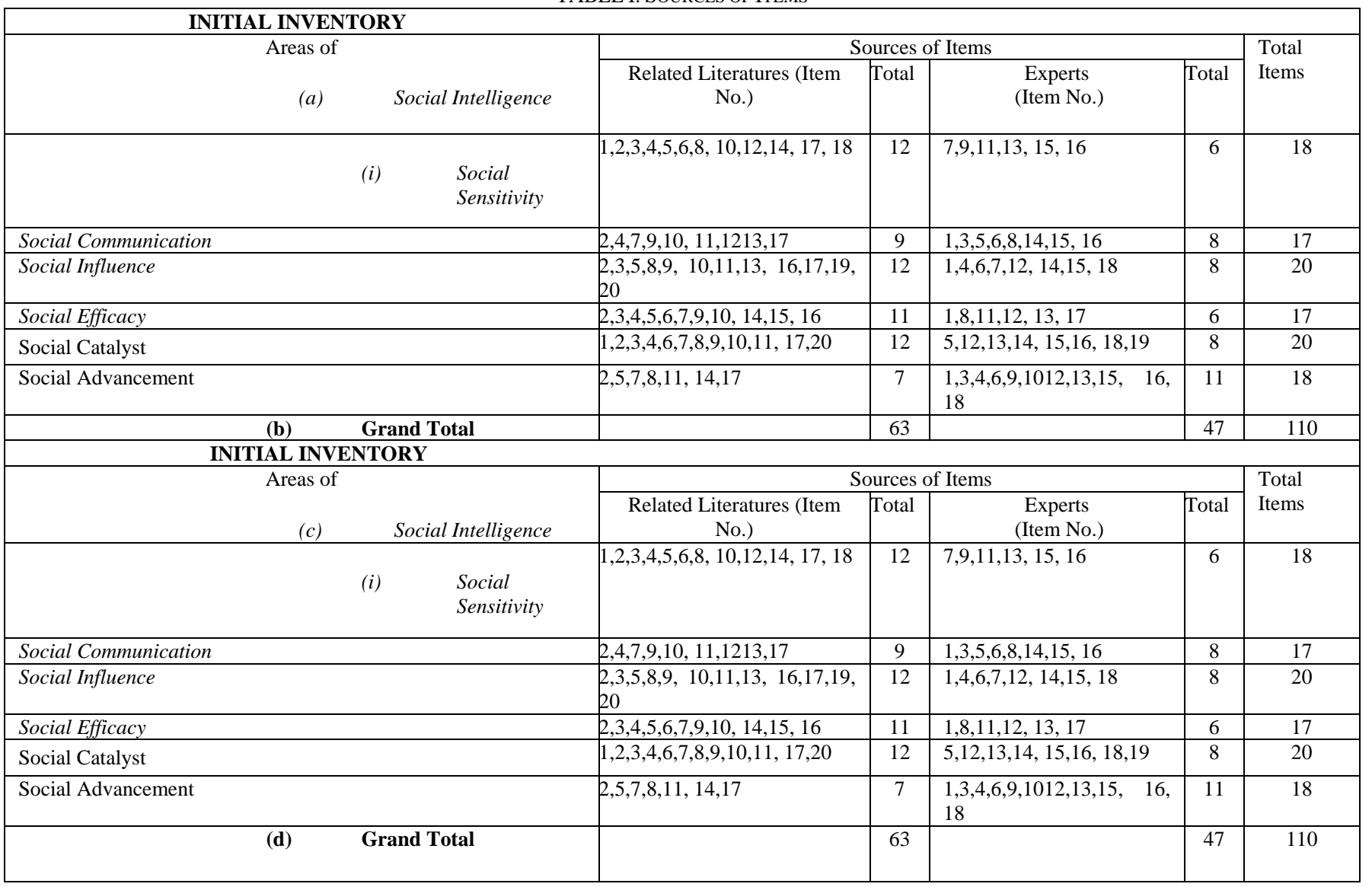

\section{B. Validation of the Inventory}

\section{1) Content}

After the items on the different areas of the inventory were finalized, they were arranged and distributed accordingly. Suggestions from experts were considered and integrated in the arrangement of items in the test. A table of specification for each area of social intelligence was prepared in order make the distributions of items adequate and proper.

TABLE II: TABLE OF SPECIFICATIONS OF THE INITIAL INVENTORY

\begin{tabular}{|c|l|c|}
\hline $\begin{array}{c}\text { AREAS OF } \\
\text { INTELLIGENCE }\end{array}$ & \multicolumn{1}{|c|}{ ITEM NUMBER } & TOTAL \\
\hline SOCIAL SENSITIVITY & $\begin{array}{l}1,2,3,4,5,6,7,8,9,10,11,12, \\
13,14,15,16,17,18\end{array}$ & 18 \\
\hline SOCIAL & $\begin{array}{l}1,2,3,4,5,6,7,8,9,10,11,12, \\
13,14,15,16,17\end{array}$ & 17 \\
COMMUNICATION & $\begin{array}{l}1,2,3,4,5,6,7,8,9,10,11,12, \\
13,14,15,16,17,18,19,20\end{array}$ & 20 \\
\hline SOCIAL INFLUENCE & $\begin{array}{l}1,2,3,4,5,6,7,8,9,10,11,12, \\
13,14,15,16,17\end{array}$ & 17 \\
\hline SOCIAL EFFICACY & $\begin{array}{l}1,2,3,4,5,6,7,8,9,10,11,12, \\
13,14,15,16,17,18,19,20\end{array}$ & 20 \\
\hline SOCIAL CATALYST & $\begin{array}{l}\mid c \\
1,2,3,4,5,6,7,8,9,10,11,12,\end{array}$ \\
\hline SOCIAL & $13,14,15,16,17,18$ & 110 \\
ADVANCEMENT & \multicolumn{1}{|c|}{} \\
\hline \multicolumn{2}{|c|}{} \\
\hline
\end{tabular}

Six (6) scales were initially prepared for the inventory. Numbers of items in different areas varied. Initially, the researcher planned to construct only fifteen (15) items for each area and only ten (10) items would be included in the final scale, but during the item construction, the items derived from literature and the items contributed by the experts exceeded fifteen. For that matter, all items were included in the initial inventory. This was because all items in the initial scale would go through validation and the number of items in the inventory would depend on the items' degree of validity.

The table shows that the initial areas of the inventory have eighteen (18) items for social sensitivity, seventeen (17) items for social communication, twenty (20) items for social influence, seventeen (17) items for social efficacy, twenty (20) items for social catalyst and eighteen (18) items for social advancement.

\section{2) Item Analysis}

Table III indicates the valid and invalid items in the areas of the inventory. Generally, all items in the initial scale were valid except those twelve (12) items that had low degree of validity.

Under social sensitivity, fifteen (15) items were valid and three (3) items were invalid, under social communication, fifteen (15) items were valid and two (2) were invalid, under social influence, eighteen (18) items were valid and two were invalid, under social efficacy, all seventeen (17) items were valid, fifteen (15) valid items and five (5) invalid items under social catalyst and all eighteen (18) items under social advancement were valid.

\section{3) Experts' evaluation}

Table IV shows the distributions of items per area in the final scale. There were six different areas on the social intelligence inventory: these are A- Social Sensitivity, BSocial Communication, C-Social Influence, D-Social Efficacy, E-Social Catalyst and F-Social Advancement. For each area, fifteen (15) items were incorporated in the final scale. The total number of items in the final scale was ninety (90). In the final scale, items 1-15 represent the 
characteristics of a socially sensitive person; items 16-30 characterized the abilities of a person in social communication; items 31-45 represent the skills an individual on social influence; items 46-60 represent the characteristics of an individual who has positive and effective working relationships with others; items 61-75 represent the individual who is a social catalyst, a person who is an agent of change in the social environment; and lastly, items 76-90 represent the characteristics of a person who is an instrument for social advancement.

TABLE III: SUMMARY OF VALID AND INVALID ITEMS

\begin{tabular}{|c|c|c|c|}
\hline Areas of Social Intelligence & & Valid Items & Invalid \\
\hline (a) & $\begin{array}{c}\text { Social } \\
\text { Sensitivity }\end{array}$ & 15 & 3 \\
\hline Social Communication & & 15 & 2 \\
\hline Social Influence & & 18 & 2 \\
\hline Social Efficacy & & 17 & 0 \\
\hline Social Catalyst & & 15 & 5 \\
\hline Social Advancement & & 18 & 0 \\
\hline (b) & Total & 98 & 12 \\
\hline
\end{tabular}

TABLE IV: TABLE OF SPECIFICATION OF THE FINAL INVENTORY

\begin{tabular}{|c|c|c|c|c|c|}
\hline Code & & Areas of In & gence & $\begin{array}{l}\text { Item } \\
\text { Number }\end{array}$ & $\begin{array}{l}\text { Total Number of } \\
\text { Items }\end{array}$ \\
\hline (c) & A & (a) & $\begin{array}{c}\text { Social } \\
\text { Sensitivity }\end{array}$ & $1-15$ & 15 \\
\hline $\mathrm{B}$ & & Social Communication & & $16-30$ & 15 \\
\hline $\mathrm{C}$ & & Social Influence & & $31-45$ & 15 \\
\hline $\mathrm{D}$ & & Social Efficacy & & $46-60$ & 15 \\
\hline $\mathrm{E}$ & & Social Catalyst & & $61-75$ & 15 \\
\hline $\mathrm{F}$ & & Social Advancement & & $76-90$ & 15 \\
\hline \multicolumn{5}{|c|}{ Grand Total } & 90 \\
\hline
\end{tabular}

A manual was prepared for the proctor or examiner of the test and it contains the guidelines and procedures for proper administration of the test, scoring, and interpretation. The Social intelligence Inventory Examiner's Manual contains a description of the inventory and its purpose; the general features of the six areas of social intelligence; the materials needed; the answer sheet; the procedures in pre-testing, testing proper, and post testing; hand scoring; table of specifications, statistical data related to validity, item analysis, reliability, and interpretation of results. Five experts in the field of psychometrics were requested to evaluate and validate the final form of the Social intelligence Inventory including the examiner's manual, test booklet, and the answer sheet. This process was conducted to rate the final scale in terms of content, scorability, economy, administrability and usability of the scale. Suggestions of the evaluators were incorporated in the corrections and revisions of the final form of the developed inventory.

In terms of content, the experts' overall rating was 4.10 which is very satisfactory. This meant that the inventory showed appropriateness and comprehensiveness in terms of content. In terms of scorability, the experts rated the inventory 4.30 or very satisfactory, which signified that the inventory manifested ease in checking and recording of the scores. In terms of economy, it was evaluated 4.20 which is very satisfactory. This means that the inventory brought about practicality in terms of instructions, scoring and interpreting the examinee(s) responses. In terms of the inventory's administrability, it was rated 4.30 or very satisfactory, this denoted that the inventory's examiner's manual is comprehensive and resulted into ease in administration. In terms of usability, the inventory was rated 4.20 or very satisfactory. This implied that it was capable of identifying the client's dominant type of social intelligence. Finally, the inventory was perceived as an additional instrument for psychological testing.

\begin{tabular}{|c|c|c|}
\hline Criteria & Mean & $\begin{array}{c}\text { Verbal } \\
\text { Description }\end{array}$ \\
\hline $\begin{array}{l}\text { 1. Sufficiency of the areas covered by } \\
\text { the inventory. }\end{array}$ & 4.2 & Very Satisfactory \\
\hline $\begin{array}{l}\text { 2. Suitability of the items representing } \\
\text { each area. }\end{array}$ & 4.0 & Very Satisfactory \\
\hline $\begin{array}{l}\text { 3. Accuracy of the items as indicated in } \\
\text { the table of specification. }\end{array}$ & 4.40 & Very Satisfactory \\
\hline $\begin{array}{l}\text { 4. Applicability of the items to target } \\
\text { clientele. }\end{array}$ & 4.0 & Very Satisfactory \\
\hline $\begin{array}{l}\text { 5. Comprehensiveness of instructions } \\
\text { and directions. }\end{array}$ & 4.60 & Excellent \\
\hline $\begin{array}{l}\text { 6. Simplicity of the constructions of } \\
\text { items. }\end{array}$ & 4.0 & Very Satisfactory \\
\hline 7. Distributions of items. & 3.80 & Very Satisfactory \\
\hline 8. Comprehensiveness of the items. & 3.80 & Very Satisfactory \\
\hline \multicolumn{3}{|l|}{ B. Scorability } \\
\hline 1. Ease in scoring & 4.40 & Very Satisfactory \\
\hline $\begin{array}{l}\text { 2. Ease in checking and recording } \\
\text { process. }\end{array}$ & 4.20 & Very Satisfactory \\
\hline \multicolumn{3}{|l|}{ C. Economy } \\
\hline $\begin{array}{l}\text { 1. Economy in scoring and interpreting } \\
\text { the inventory test. }\end{array}$ & 4.20 & Very Satisfactory \\
\hline 2. Economy in reading instructions. & 4.20 & Very Satisfactory \\
\hline \multicolumn{3}{|l|}{ D. Administrability } \\
\hline 1. Ease in administering the inventory. & 4.20 & Very Satisfactory \\
\hline $\begin{array}{l}\text { 2. Comprehensiveness of the } \\
\text { Inventory's Manual. }\end{array}$ & 4.40 & Very Satisfactory \\
\hline \multicolumn{3}{|l|}{ E. Usability } \\
\hline $\begin{array}{l}\text { 1. Representation of the clients' } \\
\text { dominant type of social intelligence. }\end{array}$ & 4.40 & Very Satisfactory \\
\hline $\begin{array}{l}\text { 2. Additional instrument for } \\
\text { psychological testing. }\end{array}$ & 4.0 & Very Satisfactory \\
\hline
\end{tabular}


TABLE VI : OVERALL EVALUATION OF EXPERTS ON THE SOCIAL INTELLIGENCE INVENTORY

\begin{tabular}{|l|c|c|}
\hline \multicolumn{2}{|c|}{ SOCIAL INTELLIGENCE INVENTORY } \\
\hline Content Validity & $\begin{array}{c}\text { GENERAL } \\
\text { MEAN }\end{array}$ & $\begin{array}{c}\text { VERBAL } \\
\text { DESCRIPTION }\end{array}$ \\
\hline Scorability & 4.10 & Very Satisfactory \\
\hline Economy & 4.30 & Very Satisfactory \\
\hline Administrability & 4.20 & Very Satisfactory \\
\hline Usability & 4.30 & Very Satisfactory \\
\hline \multicolumn{1}{|c|}{ Grand Mean } & 4.20 & Very Satisfactory \\
\hline
\end{tabular}

TABLE VII: RELIABILITY INDEX OF THE SOCIAL INTELLIGENCE INVENTORY'S INITIAL AND FINAL SCALE

\begin{tabular}{|ll|c|c|}
\hline Scale & Reliability Index & Description & Very high degree of reliability \\
\hline & (b) $\quad \begin{array}{c}\text { Initial } \\
\text { Scale }\end{array}$ & 0.987 & Very high degree of reliability \\
\hline Final Scale & & 0.989 & V \\
\hline
\end{tabular}

\section{4) Reliability test}

Table VII reflected the reliability index of the developed Social Intelligence Inventory (SII) using the coefficient alpha. In the initial scale, the inventory had a reliability index of 0.987 signifying a very high degree of reliability. In the final scale, its reliability index was 0.989 which only proved and showed that the inventory scale had a very high reliability or consistency within its sub- areas.

\section{Conclusions}

Based on the findings of this study, the following conclusions were drawn:

1) The items constructed in the developed social intelligence inventory represented the different areas of social intelligence of college students.

2) The items in the scale discriminated the students as to the indicators of social intelligence.

3) The items contained in the inventory were all statistically valid.

4) The experts rated the scale very satisfactory.

5) The Social Intelligence Inventory (SII) had a very high reliability index.

\section{RECOMMENDATIONS}

Based on the findings and conclusions, the following are strongly recommended:

1) The SII could be used by any educational institution, organization, and company in assessing their employee(s)' or student(s)' social competence.

2) The Social Intelligence Inventory (SII) was designed and should be administered only to college students. However, adults and professionals who were once college students could also use this test. But the norms of this test are not applicable to high school students and elementary pupils. Guidance offices could use the inventory as another assessment tool for students' characteristics.

3) Results obtained from the inventory should be kept with confidentiality and should not be disclosed to anybody without permission from the examinee or proper authority.

4) Results of the Social Intelligence Inventory (SII) should not be used to discriminate students (individuals) as this may possibly create feelings of
As reflected in Table VI, the social intelligence inventory gained from the experts had a grand mean of 4.22. The experts, who evaluated the inventory, perceived that its content, scorability, economy, administrability, and usability were very satisfactory. The result was that the inventory could be used in identifying the dominant type of a person's social intelligence. inadequacy and hostility among students who were found to be poor in social intelligence.

5) The Social Intelligence Inventory (SII) could be used by teachers in discovering the social competencies of their students. This is to help them develop a better and healthy learning and social environment for the students.

6) Human resource personnel of companies and organizations could use this inventory in assessing the social skills of their employee(s) and/ or prospective employee(s) who are college graduate or on the college level.

7) Development and validation of instructional materials and modules based on social intelligence could be devised by using the characteristics of students under each level of social skill. This will help the students in enhancing their social competencies.

8) Further validation of this Social Intelligence Inventory (SII) using other/different methods and procedures of validating and testing the reliability is recommended for future research.

9) A permission should be secured from the author of this study if the SII is intended to be used by any person, organization, institution or company.

\section{REFERENCES}

[1] E. L. Thorndike, "Intelligence and its use," Harper's Magazine, vol 140, pp. 227-235, 1920.

[2] F. A. Moss and T. Hunt, "Are You Socially Intelligent?" Scientific American, vol. 137, pp. 108-110, 1927.

[3] J. F. Kihlstrom and N. Cantor, "Social Intelligence and Personality: There's Room for Growth," in R. S. Wyer and T. K. Srull (eds), Advances in Social Cognition, vol. 2 pp. 197-214, Hillsdale, N.J.: Erlbaum, 1989.

[4] H. Gardner, "Frames of Mind: The Theory of Multiple Intelligences," Basic Books, New York, 1983.

[5] K. Albrecht, Social Intelligence: The New Science of Success, 1983.

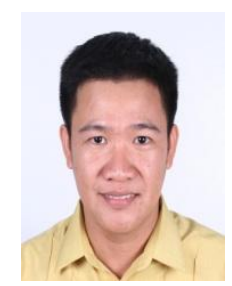

Erwin P. Lacanlale is the present research chairperson of the College of Arts and Social Sciences, Tarlac State University, Tarlac City, Philippines. Dr. Lacanlale graduated Cum Laude in his Bachelor of Arts in Social Sciences major in Behavioral Studies and a degree holder of Bachelor of Secondary Education major in Social Studies and a licensed teacher. He also holds a Master of Arts in Education major in Guidance and Counseling and Doctor of Education major in Educational Management. Dr. Lacanlale has various paper presentations and publications both in the local and international conferences and journals. He is a faculty member of the Social Sciences Department and of the Psychology Department of the College of Arts and Social Sciences, and a faculty member of the Graduate Studies at the Tarlac State University and St. La Salle University of Bacolod teaching master and doctorate students. 